\title{
Формирование оптимального инвестиционного портфеля высокотехнологичных проектов в рамках научно- образовательного центра мирового уровня
}

\author{
Лавриненко Е.А., Бондарева Я.Ю. \\ Белгородский государственный национальный исследовательский университет, \\ Россия, 308000, г. Белгород, ул. Победы, д. 85 \\ E-mail: lavrinenko_ea@mail.ru_bondareva_ya@bsu.edu.ru
}

\begin{abstract}
Аннотация. Формирование инвестиционного портфеля высокотехнологичных проектов в рамках научно-образовательного центра мирового уровня является важным этапом разработки инвестиционной стратегии региона, от которого зависит эффективность дальнейших управленческих решений, рост социально-экономических показателей и др. В статье представлена многометодная модель формирования оптимального (диверсифицированного) портфеля глобальноконкурентоспособных, высокотехнологичных инвестиционных проектов, предложенных для реализации в рамках научно-образовательных центров (НОЦ) мирового уровня. Предложена методика оценки степени влияния проектов на территориально-отраслевую социализацию региона. Разработана десятибалльная шкала оценки «возможностей» инвестиционного высокотехнологичного проекта. Предложена система оценки рисков инвестиционных проектов. Представлена модель концептуального инвестиционного высокотехнологичного проекта.
\end{abstract}

Ключевые слова: многометодная модель, территориально-отраслевая специализация, стейкхолдеры, оценка рисков, оценка возможностей.

Благодарности: исследование выполнено в рамках государственного задания НИУ «БелГУ» FZWG2020-0016, тема проекта «Фундаментальные основы глобальной территориально-отраслевой специализации в условиях цифровизации и конвергенции технологий».

Для цитирования: Лавриненко Е.А., Бондарева Я.Ю. 2021. Формирование оптимального инвестиционного портфеля высокотехнологичных проектов в рамках научно-образовательного центра мирового уровня. Экономика. Информатика. 48(4): 650-662. DOI: 10.52575/2687-0932-202148-4-650-662.

\section{Formation of an optimal investment portfolio of high-tech projects within the framework of a world-class scientific and educational center}

\author{
Elena A. Lavrinenko, Yana Yu. Bondareva \\ Belgorod State National Research University, \\ 85 Pobedy St, Belgorod, 308000, Russia \\ E-mail: lavrinenko_ea@mail.ru_bondareva_ya@ bsu.edu.ru
}

\begin{abstract}
The formation of an investment portfolio of high-tech projects within the framework of a world-class scientific and educational center is an important stage in the development of the investment strategy of the region, on which the effectiveness of further management decisions, the growth of socio-economic indicators, etc. depends. The article presents a multimode model for the formation of an optimal (diversified) portfolio of globally competitive, high-tech investment projects proposed for implementation within the framework of world-class scientific and educational centers (RECs). A methodology for assessing the degree of influence of projects on the territorial and sectoral specialization of the region is proposed. A ten-point scale for assessing the "capabilities" of an investment high-tech project has been developed. The system of risk assessment of investment projects is proposed. A model of a conceptual high-tech investment project is presented.
\end{abstract}


Keywords: multimethod model, territorial and industry specialization, stakeholders, risk assessment, opportunity assessment.

Acknowledgements: the research was carried out within the framework of the state assignment of National Research University "BelSU" FZWG-2020-0016, the topic of the project "Fundamental foundations of global territorial and industry specialization in the context of digitalization and technology convergence"

For citation: Lavrinenko E.A., Bondareva Ya.Yu. 2021. Formation of an optimal investment portfolio of high-tech projects within the framework of a world-class scientific and educational center. Economics. Information technologies. 48(4): 650-662 (in Russian). DOI: 10.52575/2687-0932-2021-48-4-650-662.

\section{Введение}

В последнее время большинство российских регионов (субъектов Российской Федерации) рассматривают переход к инновационной цифровой экономике в качестве определяющего условия конкурентоспособного позиционирования как на российском, так и на мировом рынке. Правительством Российской Федерации для построения инновационной экономики поставлена задача по индустриализации страны, в рамках которой необходимо создавать и развивать высокотехнологичные и наукоемкие предприятия, отвечающие или превосходящие современные мировые стандарты и требования [Белякова, Фалалеев, Шишкина, 2014]. Переход к инновационному развитию предполагает формирование комплекса наукоемких отраслей и расширение позиций на мировых рынках высокотехнологичной продукции. Основной задачей регионов Российской Федерации является обеспечение мировой конкурентоспособности товаропроизводителей. Это объясняется тем, что освоение масштабов региональных рынков по высокотехнологичным товарам и услугам позволит обеспечить достаточно высокий статус в мировом масштабе [Прогноз долгосрочного социально-экономического развития Российской Федерации на период до 2030 года, 2021]. На данном этапе существует необходимость структурирования множества комплексов наукоемких производств.

По данным Всемирного банка, динамика ежегодного российского экспорта высокотехнологичной продукции находилась в пределах около 3 млрд долл., что в пять раз меньше, чем аналогичный показатель Таиланда, в десять раз меньше, чем аналогичный показатель КНР, и в 14 раз меньше, чем аналогичный показатель Республики Корея [Прогноз долгосрочного социально-экономического развития Российской Федерации на период до 2030 года, 2021]. Причем доля России к уровню экспорта США составляет около 2 \%, Японии и Германии $-3 \%$, Франции и Великобритании - 7 \% [Прогноз долгосрочного социальноэкономического развития Российской Федерации на период до 2030 года, 2021]. Для преодоления негативного разрыва в темпах роста экспорта высокотехнологичной продукции в России были сформированы национальные проекты на период 2019-2024 гг.

Создание научно-образовательных центров (НОЦ) мирового уровня является частью одного из приоритетных национальных проектов «Наука». На данный момент в Российской Федерации действует порядка 14 научно-образовательных центров мирового уровня. Деятельность данных центров базируется на интеграции образовательного, научно-исследовательского и технологического процессов. Необходимость их создания и развития объясняется возможностью генерации большего числа качественно новых научных идей в рамках центров и университетов, и доведения инновационных идей до рынка с помощью стейкхолдеров.

Объединение ведущих научных и образовательных организаций, а также предприятий и организаций реального сектора экономики, позволяет сформировать в рамках НОЦ мирового уровня инвестиционный портфель высокотехнологичных проектов.

В Методических рекомендациях [Министерство науки и высшего образования РФ, 2021] «портфель основных технологических проектов» представляет собой перечень технологических проектов, содержащий мероприятия и другие работы, включая образовательные программы, 
объединенные с целью достижения более эффективного управления и повышения общей капитализации активов в логике управления инвестициями в рамках единой стратегии центра по направлениям. Портфель формируется по основным принципам эффективности управления и финансирования с распределением доходности и рисков.

Инвестиционный портфель формируется управляющим советом центра, при этом не имея чёткого механизма его формирования. Так же проблемой формирования инвестиционного портфеля в рамках НОЦ мирового уровня остается тот факт, что проекты, предлагаемые для рассмотрения в рамках НОЦ, являются «концептуальными», т. е. предлагаются на уровне инновационной идеи, что является проблематичным при оценке финансирования и рисков проекта.

В данной статье предлагается многометодная модель формирования оптимального инвестиционного портфеля высокотехнологичных проектов в рамках НОЦ мирового уровня, учитывая перспективную территориально-отраслевую специализацию региона.

\section{Объекты и методы исследования}

Формирование оптимального инвестиционного портфеля является одним из ключевых вопросов современных экономических систем. Основу данной области положили работы таких ученых, как Г. Марковиц [Симоненкова, 2017], У. Шарп [Уильям Ф. Шарп, Гордон, 2001], а также М. Скоулс и Ф. Блэк (Edwin and Gruber, 1997) [Буянова, Саркисов, 2016]. Данные работы представляли собой теоретическое обоснование существования оптимального портфеля и возможности его построения, однако ни в одной модели не указан универсальный набор факторов, при помощи которого можно составлять оптимальный инвестиционный портфель высокотехнологичных проектов в рамках научно-образовательного центра.

В работе используется имитационное моделирование, метод анализа иерархических структур, многометодная модель формирования инвестиционного проекта с использованием методов количественного и качественного анализа рисков [Ашинова, Чиназирова, Кадакоева, Гишева, 2020], возможностей.

\section{Результаты и их обсуждение}

Формируя оптимальный инвестиционный портфель высокотехнологичных проектов, в первую очередь управляющий совет [Министерство науки и высшего образования РФ, 2021] НОЦ мирового уровня, обращает внимание на то, подходит ли данный инновационный проект под перспективную территориально-отраслевую специализацию региона, так как реализация данных проектов позволяет повысить конкурентоспособность территории за счет привлечения природных ресурсов, благоприятных климатических условий и имеющегося у региона научного и кадрового потенциалов. В таблице 1 представлена территориальноотраслевая специализация регионов РФ.

Представленные в данной таблице регионы являются непосредственными участниками НОЦ мирового уровня. Участники НОЦ, реализующие высокотехнологичные проекты, должны быть готовы к тому, что время выхода на рынок напрямую связано с конкурентоспособностью, несоблюдение сроков не может быть фатальным, но это может повредить конкурентным позициям, поэтому особо важным является ресурсная готовность региона к реализации данных проектов [Грачева, Глебова, Мельникова, 2019].

Оценка высокотехнологичных инвестиционных проектов (ВИП) в соответствии с территориально-отраслевой специализацией региона является достаточно проблематичной в связи со спецификой данных инвестиционных проектов и сложностью их отнесения к той или иной отрасли специализации. Высокотехнологичные проекты могут быть как узконаправленными, так и иметь широкий спектр задействованных в реализации и дальнейшем производстве отраслей. Поэтому предлагается при формировании инвестиционного портфеля высокотехнологичных проектов оценивать уровень их влияния на региональное развитие (таблица 2). 
Территориально-отраслевая специализация регионов РФ

Territorial and sectoral specialization of the regions of the Russian Federation

\begin{tabular}{|l|l|}
\hline \multicolumn{1}{|c|}{ Регион } & \multicolumn{1}{|c|}{ Отраслевая специализация } \\
\hline Белгородская область & $\begin{array}{l}\text { Сельское хозяйство, животноводство, черная металлургия, пищевая } \\
\text { промышленность, химическая промышленность, машиностроение и } \\
\text { др. }\end{array}$ \\
\hline Кемеровская область & Добыча полезных ископаемых, лесная промышленность и др. \\
\hline $\begin{array}{l}\text { Нижегородская } \\
\text { область }\end{array}$ & $\begin{array}{l}\text { Обработка древесины, производство бумаги, производство } \\
\text { лекарственных препаратов и др. }\end{array}$ \\
\hline Пермский край & $\begin{array}{l}\text { Добыча полезных ископаемых, машиностроение, химическая } \\
\text { промышленность и др. }\end{array}$ \\
\hline Тюменская область & $\begin{array}{l}\text { Нефтегазовая промышленность, производство металлических изделий, } \\
\text { пищевая промышленность и др. }\end{array}$ \\
\hline Самарская область & Производство автотранспортных средств, электронных изделий и т. д. \\
\hline Тульская область & $\begin{array}{l}\text { Машиностроение, военная техника, пищевая промышленность, } \\
\text { химическая промышленность и др. }\end{array}$ \\
\hline Мурманская область & Производство арктической техники, судостроительство, рыболовство и др. \\
\hline \multicolumn{2}{|c}{ *составлено автором }
\end{tabular}

Таблица 2

Table 2

Коэффициент влияния высокотехнологичного проекта на развитие приоритетных территориально-отраслевых специализаций региона

The coefficient of influence of a high-tech project on the development of priority territorial and sectoral specializations of the region

\begin{tabular}{|c|c|c|c|}
\hline \multirow{2}{*}{ Проекты } & \multicolumn{3}{|c|}{ Коэффициент (К) влияния } \\
\cline { 2 - 4 } & Слабое (0-3) & Среднее (4-7) & Бесспорное (8-10) \\
\hline$B И \Pi_{1}$ & 1 & - & - \\
\hline$B И \Pi_{2}$ & - & 5 & - \\
\hline$\ldots$ & - & - & 8 \\
\hline$B И \Pi_{n}$ & - & - & 8 \\
\hline
\end{tabular}

Степень влияния проекта на территориально-отраслевую специализацию региона:

$$
S=\frac{Q_{r p}}{q_{r}} K
$$

где,$Q_{r p}$ - планируемый объем выпускаемой продукции после реализации проекта;

$q_{r}$ - объем валового выпуска r-отрасли специализации в регионе.

При оценке каждого предлагаемого проекта выстраивается рейтинг наиболее влиятельных проектов на социально-экономическое развитие региона.

При рассмотрении инвестиционного портфеля НОЦ мирового уровня «Инновационные решения в АПК» (Белгородская область) мы можем видеть направленность проектов на развитие агропромышленного комплекса, внедрение новых передовых технологий, селекционно-генетические исследования, здоровьесберегающие технологии. Направления деятельности НОЦ ежегодно расширяются, по отчёту управляющего совета за 2021 год, в портфель НОЦ «Инновационные решения в АПК» планируется включить проекты внедрения искусственного интеллекта в уходе за животными, реализация данного проекта зависит от высокого уровня кадрового потенциала НОЦ, но при реализации данный проект будет непосредственно оказывать высокую степень влияния на агропромышленный комплекс региона. 
1.Создание промышленного комплекса биотехнологического культивирования спирулины.

2. Разработка конкурентоспособной технологии микробиологического синтеза аминокислоты L-треонин. 3. Разработка технологии производства протеиновой муки из личинок мухи «Черная львинка» Hermetia illucens.

4.Получение гиполлергенных резорбирующихся мембран из биологических продуктов.

5. Твердофазная ферментация соевого шрота и оптимизация его аминокислотного состава.

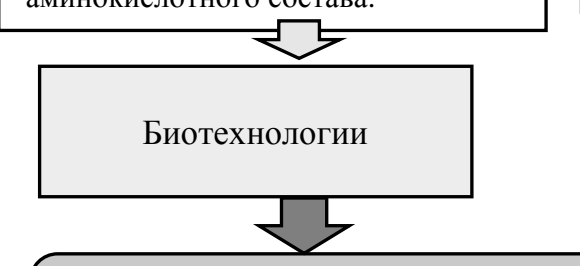

\section{Портфель инвестиционных проектов НОЦ «Инновационные решения в АПК»}

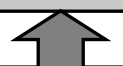

4.Селекционно-генетические исследования, клеточные технологии и генная инженерия (в области растениеводства)

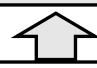

1.Разработка эффективной технологии светорегулируемого выращивания культур в условиях защищенного грунта.

2. Селекционно-генетические исследования зернового комплекса кукурузы.

3. Создание генотипов озимой пшеницы с повышенной перевариваемостью зерна за счет изменения белкового и крахмального комплекса эндосперма.

4. Разработка научно-технических решений и организация производства наноструктурных стимуляторов роста и средств защиты растений на основе наночастиц металлов.

5. Разработка технологии производства микробиологических удобрений для управления ростом и развитием растений.

6. Создание интеллектуального сервиса распознавания заболеваний зерновых культур на основе технологии машинного обучения и междисциплинарных знаний в составе цифровой платформы.

1.0 предложениях по переработке отходов производства и потребления в объеме $600 \quad 000$ тонн в год с производством альтернативного топлива RDF в объеме 150000 тонн в год и вовлечение отсортированных отходов в хозяйственный оборот в качестве втор.

2. Создание комплексной технологии переработки гипсосодержащих отходов промышленных предприятий.

3. Ресурсо-энергосберегающая технология по комплексной переработке и утилизации ТКО с использованием внутренних ресурсов и получения товарной продукции объемом 1000 тонн в год.

4. Производственный комплекс глубокой переработки растительных масел на основе инновационной технологии управляемого органического синтеза.

5. Твердооксидные топливные элементы (ТОТЭ) для

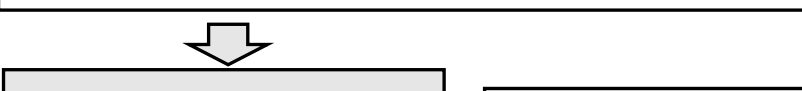

Рациональное природопользование

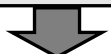

3.Здоровьесберегающие технологии: производство продовольствия и ветпрепаратов

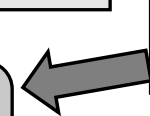

1.Создание тест-систем для детекции и типизации вируса лейкоза крупного рогатого скота на основе молекулярногенетических методов диагностики возбудителя в системе противолейкозных мероприятий.

2.Создание синтетических антибактериальных препаратов комбинированного действия с использованием молекулярного дизайна для применения в условиях развитого промышленного животноводства

3.Создание и внедрение технологии «инновационный аналитический инструмент» для оценки и формирования кадрового потенциала агропромышленного комплекса Белгородской области

4. Увеличение продуктивного потенциала индустриальной аквакультуры Белгородской области за счет внедрения комбикормов направленного действия

5. Разработка технологии моюще-дезинфицирующих средств на основе экологически безопасных компонентов для предприятий агропромышленного комплекса и общественного питания

Рис. 1. Инвестиционный портфель НОЦ «Инновационные решения в АПК»

Fig. 1. Investment portfolio of REC "Innovative solutions in agriculture" 
Проекты, представленные на рисунке 1, на данном этапе находятся не только на стадии концептуальной идеи, но некоторые из них уже проходят стадию реализации:

1. Проект «Разработка интеллектуальной роботизированной системы биобанка для хранения и транспортировки биологического материала»: сформирована база данных фактических условий хранения биообразцов; разработан алгоритм технологического процесса биобанкирования и др.

2. Проект «Создание высокотехнологичного крупномасштабного производства животного белка из личинок мух»: прошел стадию промышленной апробации.

3. Проект «Создание комплексной технологии переработки гипсосодержащих отходов промышленных предприятий»: в 2021 год оптимизированы параметры (температура, влажность исходного сырья) изготовления гипсовых вяжущих из гипсосодержащих отходов, установлена возможность использования цитрогипса и др.

4. Проект «Разработка технологии производства светорассеивающей добавки и текстуры (шагрень) для производства поликарбонатных светорассеивателей, применяемых в сфере растениеводства, животноводства и промышленном освещении»: подобраны технологические параметры оборудования по способу и очередности внесения компонентов смеси для осуществления компаундирования; подобраны светорассеивающие добавки на основе акриловых и стеклянных микросфер отечественного производства; произведена апробация эксплуатационных и оптических свойств светорассеивателей и др.

5. Проект «Производственный комплекс глубокой переработки растительных масел на основе инновационной технологии управляемого органического синтеза»: выполнены комплексный анализ технологической схемы получения алкидных смол, применяемых в химической и лакокрасочной промышленности, определены основные этапы технологического процесса получения алкидных смол, а также анализ основного технологического оборудования и определены технические параметры комплекса и др.

6. Проект «Ресурсо-энергосберегающая инновационная технология по комплексной переработке ТКО полного технологического цикла обращения с отходами, с получением различных видов товарной продукции и электрической энергии»: проведен комплекс теоретических, экспериментальных исследований, моделирование на созданных стендовых установках технологических процессов переработки полимерных и базальтовых волокнистых отходов для получения на производственной площадке ООО «ТК «Экотранс» композиционных смесей и изделий из них.

Успешная реализация высокотехнологичных проектов в рамках НОЦ мирового уровня является стимулом для дальнейшего привлечения региональных стейкхолдеров и формирования оптимального инвестиционного портфеля высокотехнологичных проектов.

Каждый высокотехнологичный проект обладает рядом возможностей, возникающих при его реализации. Выявление и оценивание наряду с рисками реализации проекта, его возможностей, позволит исключить проекты, не несущие для региона и страны в целом социально-экономического эффекта.

В таблице 3 представлена десятибалльная шкала оценивания «возможностей» инвестиционного высокотехнологичного проекта.

Оценивая каждый потенциальный для реализации в рамках НОЦ проект, эксперт должен опираться на представленные в таблице 3 критерии и присваивать балл, соответствующий степени значимости проекта. Наличие более трех критериев в одной степени значимости позволяет лицу, принимающему решение присвоить проекту данную степень от 1 до 10, соответственно.

Проекты, подходящие по критериям в шкале значений от 3 до 10, рекомендуются для принятия в инвестиционный портфель в рамках НОЦ мирового уровня. 
Десятибалльная шкала оценивания «возможностей» инвестиционного высокотехнологичного проекта

A ten-point scale for assessing the "possibilities" of an investment high-tech project

\begin{tabular}{|c|c|}
\hline $\begin{array}{c}\text { Степень } \\
\text { значимости }\end{array}$ & Критерии \\
\hline 1 & $\begin{array}{l}\text { Низкая экономическая и социальная значимость для региона; не предусмотрено } \\
\text { создание новых рабочих мест; не соответствует территориально-отраслевой } \\
\text { специализации региона; способствует загрязнению окружающей среды. }\end{array}$ \\
\hline 2 & $\begin{array}{l}\text { Средняя экономическая значимость для региона; отсутствие необходимости } \\
\text { привлечения научного сообщества; не соответствует территориально-отраслевой } \\
\text { специализации региона; продукт не способен конкурировать на региональном } \\
\text { рынке с предыдущими менее высокотехнологичными аналогами. }\end{array}$ \\
\hline 3 & $\begin{array}{l}\text { Средняя экономическая значимость для региона; предусмотрена организация до } \\
10 \text { новых рабочих мест; продукт является востребованным на региональном } \\
\text { рынке; соответствует экологическим нормам. }\end{array}$ \\
\hline 4 & $\begin{array}{l}\text { Способствует развитию инновационных технологий в регионе; продукт } \\
\text { востребован на региональном рынке; организация до } 50 \text { новых рабочих мест; } \\
\text { производство соответствует экологическим нормам. }\end{array}$ \\
\hline 5 & $\begin{array}{l}\text { Соответствует экономическим способностям региона; организация до } 100 \text { новых } \\
\text { рабочих мест; привлечение ведущих учёных из других регионов; способствует } \\
\text { межрегиональному взаимодействию; соответствует экологическим нормам. }\end{array}$ \\
\hline 6 & $\begin{array}{l}\text { Привлечение ведущих ученных России и зарубежных стран; более } 200 \text { новых } \\
\text { рабочих мест; способствует межрегиональному взаимодействию; соответствует } \\
\text { территориально-отраслевой специализации региона; отсутствует влияние на } \\
\text { экологию. }\end{array}$ \\
\hline 7 & $\begin{array}{l}\text { Привлечение ведущих ученных России и зарубежных стран; более } 300 \text { новых } \\
\text { рабочих мест; способствует межрегиональному взаимодействию; соответствуе } \\
\text { территориально-отраслевой специализации региона, отсутствует влияние на } \\
\text { экологию. }\end{array}$ \\
\hline 8 & $\begin{array}{l}\text { Способствует снижению экологических загрязнений в регионе; повышает } \\
\text { конкурентоспособность региона; соответствует территориально-отраслевой } \\
\text { специализации региона; более } 500 \text { новых рабочих мест; способствует } \\
\text { привлечению российских и зарубежных ведущих учёных; выполняет } \\
\text { импортозаменяюшую функцию. }\end{array}$ \\
\hline 9 & $\begin{array}{l}\text { Способствует развитию научных лабораторий; соответствует территориально- } \\
\text { отраслевой специализации региона; высокая экономическая и социальная } \\
\text { значимость для региона; более } 1000 \text { новых рабочих мест; способствует } \\
\begin{array}{l}\text { повышению конкурентоспособности региона; способствует снижению } \\
\text { экологических загрязнений в регионе. }\end{array}\end{array}$ \\
\hline 10 & $\begin{array}{l}\text { Способствует крупным международным научным изысканиям; соответствует } \\
\text { территориально-отраслевой специализации региона; компенсация стратегически } \\
\text { важного продукта, на национальном рынке; повышает конкурентоспособность } \\
\text { региона на мировом рынке. }\end{array}$ \\
\hline
\end{tabular}

*составлено автором

Моделируя «возможности» высокотехнологичных инвестиционных проектов (ВИП), мы прибегаем к методу анализа иерархических структур [Саати, 1993].

Каждый высокотехнологический проект обладает совокупностью возможностей (рис. 2). 


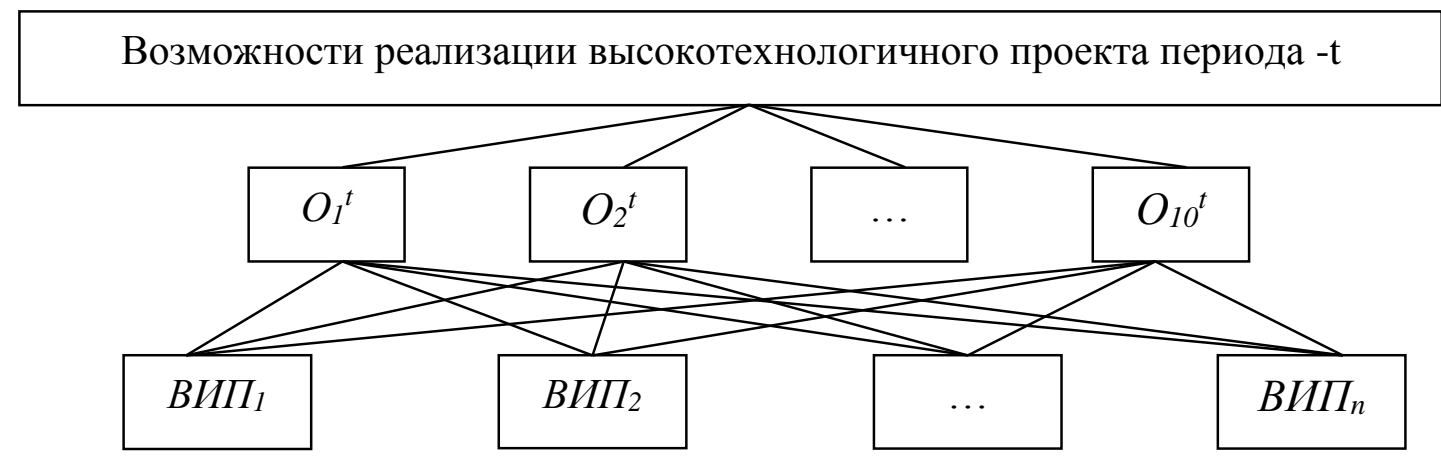

Рис. 2. Имитационная модель «Возможности» (составлено автором)

Fig. 2. Simulation model of "Opportunities" (compiled by the author)

В качестве $O_{1}{ }^{\mathrm{t}}, \mathrm{O}_{2}{ }^{\mathrm{t}}, \ldots . O_{\mathrm{n}}{ }^{\mathrm{t}}$ выступают «возможности», представленные в таблице 1 . Возможности определяются с учётом временного периода проведения оценки-(t). Так как при повторной оценке в ходе реализации проекта могут появиться новые «возможности».

Наличие «возможностей» определяется на всех стадиях реализации высокотехнологичного инвестиционного проекта, что позволяет выявить наиболее перспективные для региона проекты и определить рейтинг имеющихся для реализации в рамках НОЦ проектов.

Так как высокотехнологичные проекты являются высокорисковыми, возникает необходимость оценки не только «возможностей», но и «рисков» проекта. Имитационное моделирование рисков позволяет управляющему совету НОЦ заглянуть за горизонт событий, выявить и нивелировать возникновение критически опасных рисков реализации проектов, тем самым обезопасив финансирование не только со стороны государства, но и непосредственно бизнес структур, участвующих в реализации данного высокотехнологичного инвестиционного проекта (рис. 3).

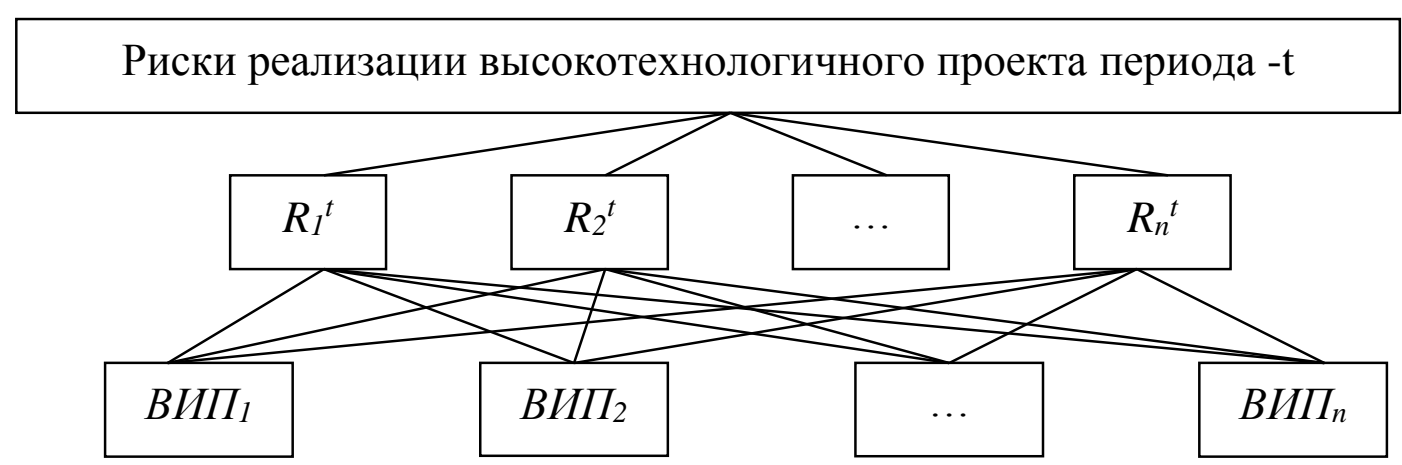

Рис. 3. Имитационная модель «Риски» (составлено автором)

Fig. 3. Simulation model "Risks" (compiled by the author)

$R_{1}{ }^{t}, R_{2}{ }^{t}, \ldots, R_{n}{ }^{t}$ - это нежелательное событие, имеющее два взаимно независимых параметра:

1) вероятность его появления на заданном интервале времени;

2) наносимый ущерб в случае свершения этого события.

Поэтому при сравнении ВИП с позиции конкретного риска учитываем наносимый ущерб, а при сравнении самих рисков как оценочных критериев учитываем вероятность проявления конкретного риска.

Риски высокотехнологичного инвестиционного проекта представлены в таблице 4. 
Риски высокотехнологичного инвестиционного проекта (составлено авторами

по [Головкова М.Г., Лашманова Н.В., 2016])

Risks of a high-tech investment project (compiled by the authors according to

[Golovkova M.G., Lashmanova N.V., 2016])

\begin{tabular}{|c|c|c|}
\hline № & Риски & 2-й уровень детализации рисков \\
\hline 1 & Контрактные & $\begin{array}{l}\text { невыполнения контрагентом по контракту своих } \\
\text { обязательств; блокирования (фактической приостановки) } \\
\text { контракта; коммерческой неэффективности контракта. }\end{array}$ \\
\hline 2 & $\begin{array}{l}\text { Программного } \\
\text { обеспечения }\end{array}$ & $\begin{array}{l}\text { непроверенные технологии; пользовательская неудовлетворенность; } \\
\text { выбор неправильной платформы; неудовлетворенность } \\
\text { пользовательских ожиданий; }\end{array}$ \\
\hline 3 & Финансовые & $\begin{array}{l}\text { инфляция; падение уровня цен; потери при реализации товара из-за } \\
\text { изменения оценки их качества и потребительной стоимости; изменение } \\
\text { курса валют. }\end{array}$ \\
\hline 4 & $\begin{array}{l}\text { Среды и } \\
\text { инструментов } \\
\text { проектирования и } \\
\text { разработки }\end{array}$ & $\begin{array}{l}\text { воздействия на цели проекта неблагоприятных событий; неточности } \\
\text { проектных разработок; сложности реализации; влияние на внешнюю и } \\
\text { внутреннюю среду предприятия. }\end{array}$ \\
\hline 5 & Организационные & $\begin{array}{l}\text { отсутствие внутреннего контроля; не разработанные документальные } \\
\text { инструкции; ошибки кадрового управления. }\end{array}$ \\
\hline 6 & Технологические & $\begin{array}{l}\text { некорректности настроек алгоритмов; нарушения качества и } \\
\text { целостности данных; нарушения в работе подрядчиков и партнеров; } \\
\text { ошибки при разработке и обновлении ИТ-систем. }\end{array}$ \\
\hline 7 & Качества & $\begin{array}{l}\text { дефекты; риск ущерба здоровью; негативное влияние на экологию; } \\
\text { невостребованность продукции. }\end{array}$ \\
\hline 8 & Командно-лидерские & $\begin{array}{l}\text { переоценка научного потенциала; остановка в развитии; одержимость } \\
\text { идеей; отсутствия обратной связи; корыстного использования } \\
\text { занимаемой должности. }\end{array}$ \\
\hline
\end{tabular}

Оценка рисков при реализации высокотехнологических проектов позволяет смягчать наносимый ущерб и отслеживать триггеры рисков.

В таблице 5 представлена комбинация последствий и вероятности рисков, что позволяет определить меру «переносимости» того или иного риска.

Комбинации последствий и вероятности рисков

Combinations of consequences and probability of risks

\begin{tabular}{|l|c|c|c|}
\hline Вероятность & Низкая & Средняя & Высокая \\
\hline Катастрофические & & А & А \\
\hline Средние & Б & Б & А \\
\hline Незначительные & В & Г & Б \\
\hline
\end{tabular}

На основе анализа возможных комбинаций последствий и вероятности рисков они могут быть ранжированы следующим образом:

А - непереносимый риск, который должен быть однозначно исключен;

Б - риск, который трудно переносим; от него следует избавиться как можно раньше;

В - переносимый риск, от которого можно избавиться по мере возможности;

Г- приемлемый риск. 
В зависимости от конкретной ситуации оценка непереносимости рисков может быть различна: если для одних проектов неудачно проведенный эксперимент может означать «непереносимый риск», то для других проектов это является «приемлемым риском», так как могут появится новые варианты развития событий.

Таким образом, концептуальный высокотехнологичный инвестиционный проект имеет следующий вид:

$$
\text { ВИП }=\left(\left\{\left(O_{1}{ }^{\mathrm{t}}, \mathrm{O}_{2}{ }^{\mathrm{t}}, \ldots O_{10}{ }^{\mathrm{t}}\right)\left(R_{1}{ }^{\mathrm{t}}, \mathrm{R}_{2}{ }^{\mathrm{t}}, \ldots R_{8}{ }^{\mathrm{t}}\right)(\mathrm{S})\right\}^{1 \mathrm{~T}}\right) .
$$

Также при принятии инвестиционного проекта немаловажным является требуемый объем финансирования, имеющийся в регионе научный и кадровый потенциал.

На рисунке 4 представлена модель инвестиционного портфеля с учётом требуемого объема финансирования, научного и кадрового потенциала, имеющихся у концептуального проекта «возможностей» и рисков.

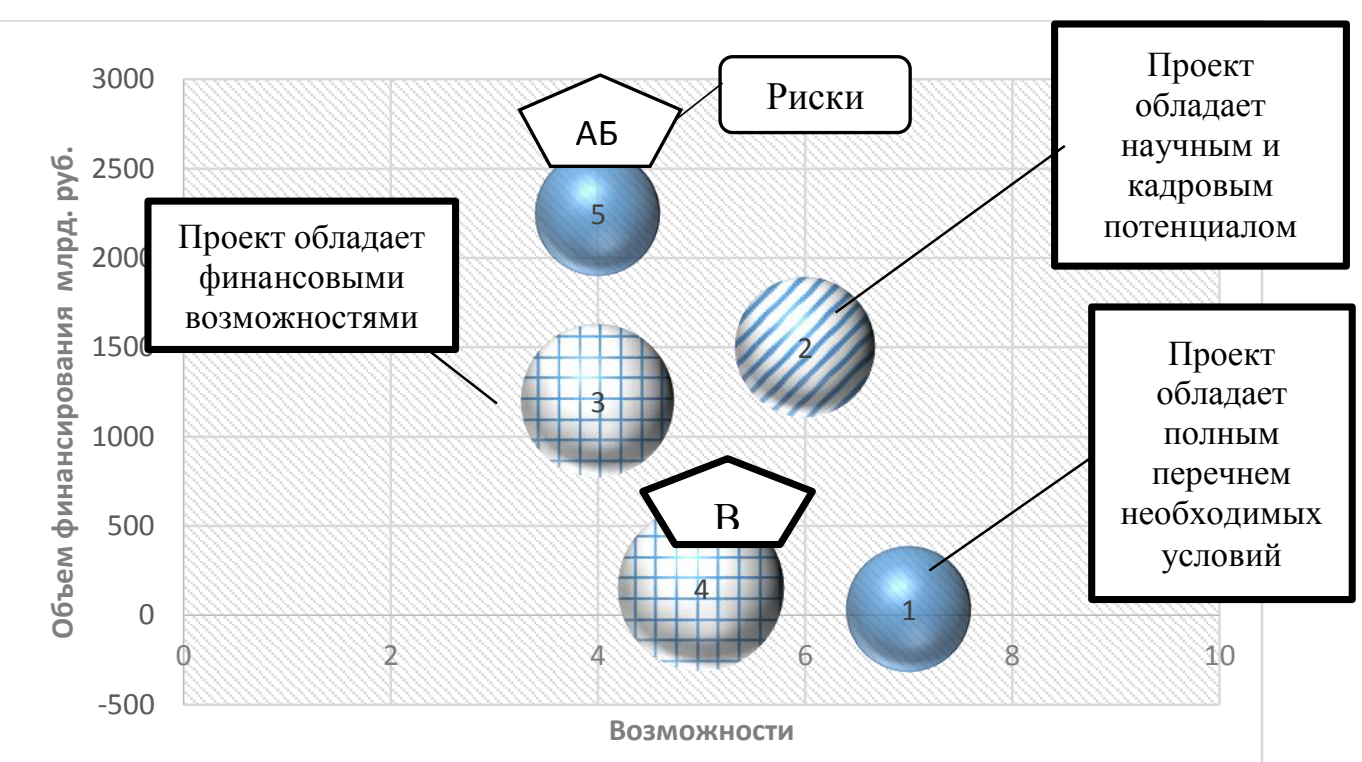

Рис. 4. Графическая интерпретация модели формирования оптимального инвестиционного портфеля высокотехнологичных проектов в рамках НОЦ мирового уровня

Fig. 4. Graphical interpretation of the model for the formation of an optimal investment portfolio of high-tech projects within the framework of a world-class REC

Как видно на рисунке 4, проекты 1 и 5 обладают всеми необходимыми условиями реализации и находятся в диапазоне от 4 до 7 по десятибалльной шкале оценивания «возможностей» инвестиционного высокотехнологичного проекта, но при этом проект 5 являются высокорисковым, так как комбинация последствий и вероятности рисков АБ указывает на наличие труднопереносимых рисков. Проекты 3 и 4 обладают финансовыми возможностями для реализации, находятся в диапазоне от 4 до 5, что позволяет данным проектам войти в инвестиционный портфель в рамках НОЦ мирового уровня и, прибегая к возможности межрегионального взаимодействия, с учётом привлечения научных кадров и других высококвалифицированных специалистов, быть реализованными. Проект 2 обладает научным и кадровым потенциалом, находится в диапазоне 6-7, что характеризует данный проект как перспективный для социально-экономического развития региона.

Многометодный подход при формировании инвестиционного портфеля высокотехнологических проектов позволяет выявить наиболее перспективные проекты в соответствии с территориально-отраслевой специализацией, при этом определив «возможности» данного проекта, полезные и важные для региона и страны в целом, и предотвратить риски (рис. 5). 


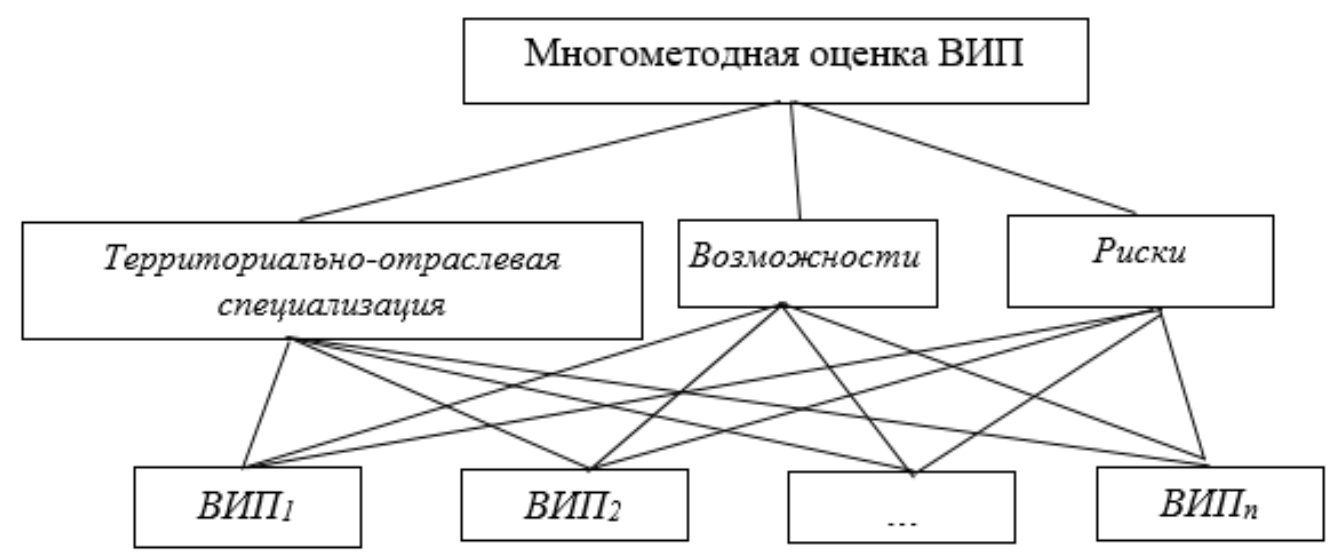

Рис. 5. Модель формирования инвестиционного портфеля высокотехнологичных проектов в рамках НОЦ мирового уровня

Fig. 5. A model for the formation of an investment portfolio of high-tech projects within the framework of a world-class REC

Перед управляющим советом НОЦ стоит сложная задача выбора проектов, реализация которых будет способствовать повышению конкурентоспособности региона, поэтому многометодный подход при формировании инвестиционного портфеля высокотехнологичных проектов является обоснованным в связи с важностью реализации данных проектов не только для региона, но и для страны в целом.

\section{Заключение}

Присутствие эффективного взаимодействия между наукой, государством и бизнесом позволит обеспечить обновление технической и технологической базы производства, снизить себестоимость, осваивать и выпускать новую конкурентоспособную продукцию, проникать на мировые рынки товаров и услуг. Поэтому немаловажным в процессе повышения инновационной активности России является решение вопросов, связанных с развитием НОЦ мирового уровня.

Региональные власти, основываясь на территориально-отраслевой специализации, должны выявлять перспективные высокотехнологичные проекты, способствующие крупным международным научным изысканиям, способные компенсировать стратегически важный продукт на национальном рынке, повышать конкурентоспособность региона на мировом рынке.

Многометодная модель формирования оптимального инвестиционного портфеля высокотехнологичных проектов в рамках НОЦ мирового уровня позволяет выявить степень влияния на территориально-отраслевую специализацию региона, «возможности» и «риски» высокотехнологичных инвестиционных проектов еще на стадии «концептуального проекта». Инвестиционный портфель в рамках НОЦ мирового уровня должен с достаточно частой периодичностью пересматриваться и дополняться новыми проектами в связи с высокими темпами инновационного развития России.

\section{Список источников}

1. Методические рекомендации по формированию программ деятельности научнообразовательных центров мирового уровня (утв. Министерством науки и высшего образования РФ 26 апреля 2021 г.). URL: https://minobrnauki.gov.ru/documents/?ELEMENT_ID=33259 (дата обращения: 01.10. 2021).

2. Прогноз долгосрочного социально-экономического развития Российской Федерации на период до 2030 года. 2021. Электронный ресурc. URL: http://www.economy.gov.ru/minec/activity/ sections/macro/prognoz/doc20130325_06 (дата обращения: 01.10. 2021). 
3. Саати Т. 1993. Принятие решений. Метод анализа иерархий. Томас Саати, пер. с англ. Р.Г. Вачнадзе. Радио и связь, 278.

4. Уильям Ф. Шарп, Гордон Дж. 2001. Инвестиции. Учебник, 1035.

\section{Список литературы}

1. Ашинова М.К., Чиназирова С.К., Кадакоева Г.В., Гишева С.Ш. 2020. Методы оценки рисков инновационных проектов. The Scientific Heritage, 54-7: 13-17.

2. Белякова, Г.Я., Фалалеев, А.Н., Шишкина, Н.А. 2014. Факторы, оказывающие влияние на качество инновационно-инвестиционных проектов создания высокотехнологичных производств. Сибирский аэрокосмический журнал, 5 (57): 221-226.

3. Буянова Е.А., Саркисов А.Р. 2016. Формирование инвестиционного портфеля на российском рынке акций при помощи непараметрического метода - дерева решений. Корпоративные финансы, 10 (1): 46-58.

4. Головкова М.Г., Лашманова Н.В. 2016. Риски реализации инновационных проектов на предприятиях ВТОЭ. Инновации, 6 (212): 119-123.

5. Грачева О.В., Глебова О.В., Мельникова О.Ю. 2019. Отличительные особенности и классификация высокотехнологичных проектов разработки и производства продукции гражданского назначения. Вопросы инновационной экономики, 9 (3): 1067-1076.

6. Носов А.Л. 2018. Стратегия повышения конкурентоспособности региона. Россия: тенденции и перспективы развития, 13-2: 147-150.

7. Симоненкова Е.В. 2017. Формирование инвестиционного портфеля по модели Марковица. Хроноэкономика, 6 (8): 86-91.

\section{References}

1. Ashinova M.K., Chinazova S.K., Kadakoeva G.V., Gisheva S.Sh. 2020. Metody ocenki riskov innovacionnyh proektov. [Methods of risk assessment of innovative projects]. The Scientific Heritage, 54-7: 13-17.

2. Belyakova, G.Ya., Falaleev, A.N., Shishkina, N.A. 2014. Faktory, okazyvayushchie vliyanie na kachestvo innovacionno-investicionnyh proektov sozdaniya vysokotekhnologichnyh proizvodstv. [Factors influencing the quality of innovation and investment projects for the creation of high-tech industries]. Sibirskij aerokosmicheskij zhurnal [Siberian Aerospace Magazine], 5 (57): 221-226.

3. Buyanova E.A., Sarkisov A.R. 2016. Formirovanie investicionnogo portfelya na rossijskom rynke akcij pri pomoshchi neparametricheskogo metoda - dereva reshenij. [Formation of an investment portfolio on the Russian stock market using a nonparametric method - a decision tree]. Korporativnye finansy [Corporate Finance], 10(1): 46-58.

4. Golovkova M.G., Lashmanova N.V. 2016. Riski realizacii innovacionnyh proektov na predpriyatiyah vtoe [The risks of implementing innovative projects at the VTE enterprises]. Innovacii [Innovations], 6 (212): 119-123.

5. Gracheva O.V., Glebova O.V., Melnikova O.Yu. 2019. Otlichitel'nye osobennosti i klassifikaciya vysokotekhnologichnyh proektov razrabotki i proizvodstva produkcii grazhdanskogo naznacheniya. [Distinctive features and classification of high-tech projects for the development and production of civil products]. Voprosy innovacionnoj ekonomiki [Issues of innovative economy], 9 (3): 1067-1076.

6. Nosov A.L. 2018. Strategiya povysheniya konkurentosposobnosti regiona. Rossiya: tendencii i perspektivy razvitiya [Strategy of increasing the competitiveness of the region. Russia: Trends and Prospects of Development], 13-2: 147-150.

7. Simonenkova E.V. 2017. Formirovanie investicionnogo portfelya po modeli Markovica. [Formation of an investment portfolio according to the Markowitz model]. Hronoekonomika [Chronoeconomics],

6 (8): 86-91.

Конфликт интересов: о потенциальном конфликте интересов не сообщалось.

Conflict of interest: no potential conflict of interest related to this article was reported. 


\section{ИНФОРМАЦИЯ ОБ АВТОРАХ}

Лавриненко Елена Александровна, кандидат экономических наук, доцент кафедры прикладной экономики и экономической безопасности Белгородского государственного национального исследовательского университета, г. Белгород, Россия

Бондарева Яна Юрьевна, кандидат экономических наук, доцент, доцент кафедры прикладной экономики и экономической безопасности Белгородского государственного национального исследовательского университета, г. Белгород, Россия

\section{INFORMATION ABOUT THE AUTHORS}

Elena A. Lavrinenko, Candidate of Economic Sciences, Associate Professor of the Department of Applied Economics and Economic Security of the Belgorod National Research University, Belgorod, Russia

Yana Yu. Bondareva, Candidate of Economic Sciences, Associate Professor, Associate Professor of the Department of Applied Economics and Economic Security of the Belgorod National Research University, Belgorod, Russia 